doi.org/ I0.5189I/rease.v8ir.3991

\title{
PERCEPÇÕES E VIVÊNCIAS DE ADOLESCENTES GRÁVIDAS
}

\author{
PERCEPTIONS AND EXPERIENCES OF PREGNANT ADOLESCENTS
}

\author{
Gabriella Fernandes Amorim ${ }^{1}$ \\ Deborah Cristina Nascimento de Oliveira ${ }^{2}$ \\ Lara Horta de Araújo Leite ${ }^{3}$ \\ Giovana Lins Basto ${ }^{4}$
}

RESUMO: Objetivo: identificar os conflitos percebidos e vivenciados por adolescentes grávidas. Métodos: trata-se de um estudo qualitativo realizado na cidade de João Pessoa $\mathrm{PB}$, o qual contou com a participação de três adolescentes com até 17 anos de idade. Resultados: sobre as experiências vivenciadas pelas participantes acerca da gravidez na adolescência, foi possível encontrar três categorias de análise que foram identificadas da seguinte forma: Importância da Família; Dilemas da Gestação Precoce e; Expectativas das jovens mães. Observou-se que apesar desse choque inicial vivido pelos familiares, fica explícita na fala das entrevistadas a importância do apoio familiar para que as adolescentes consigam lidar com a gestação numa fase precoce da vida. Conclusões: conclui-se que a gravidez na adolescência é um fenômeno heterogêneo, que sofre elevada influência do contexto social em que a adolescente está inserida.

Palavras-chave: Gestação precoce. Adolescentes. Percepção. Sexualidade. Família.

ABSTRACT: Objective: identify the conflicts perceived and experienced by pregnant adolescents. Methods: this is a qualitative study carried out in the city of João Pessoa - PB, and counted on the participation of three adolescents up to 17 years of age. Results: regarding the experiences of the participants about teenage pregnancy, it was possible to find three categories of analysis that were identified as follows: Importance of the Family; Dilemmas of Early Pregnancy e; Expectations of young mothers. It was observed that despite this initial shock experienced by family members, it is clear in the interviewees' statements the importance of family support for adolescents to be able to deal with pregnancy at an early stage of life. Conclusions: it is concluded that teenage pregnancy is a heterogeneous phenomenon, which is highly influenced by the social context in which the adolescent is inserted.

Keywords: Early Pregnancy. Adolescents. Perception. Sexuality. Family.

\footnotetext{
${ }^{\mathrm{I}}$ Acadêmica de Medicina Faculdade de Medicina Nova Esperança/FAMENE

${ }^{2}$ Acadêmica de Medicina Faculdade de Medicina Nova Esperança/FAMENE

${ }^{3}$ Acadêmica de Medicina Faculdade de Medicina Nova Esperança/FAMENE

${ }^{4}$ Acadêmica de MedicinaFaculdade de Medicina Nova Esperança/ FAMENE. Email:giovanalinsı23@hotmail.com.
} 


\section{INTRODUÇÃO}

A Organização Panamericana de Saúde, em seu relatório intitulado "Aceleração do progresso em direção à redução da gravidez na adolescência na América Latina e no Caribe”, considera o período da adolescência dividido em duas faixas etárias: A primeira, de ro a 16 anos, e segunda de 16 a 20 anos, e alerta para o fato de que a taxa global de gravidez na adolescência é estimada em 46 nascimentos por I.ooo meninas, enquanto as taxas de gravidez na adolescência na América Latina e no Caribe permanecem a segunda mais alta do mundo - estimada em 66,5 nascimentos por I.ooo meninas entre is e 19 anos, superados apenas pelos da África Subsaariana'.

Se analisarmos os dados de nosso país, anualmente, cerca de $18 \%$ dos brasileiros nascidos são filhos de mães adolescentes. Em números absolutos isso representa 400 mil casos por ano. No mundo, são aproximadamente 16 milhões de adolescentes de 15 a 19 anos; e 2 milhões de adolescentes menores de 15 anos. Globalmente, o risco de morte materna se duplica entre mães com menos de 15 anos em países de baixa e média renda ${ }^{\mathrm{I}}$.

Sabe-se que muitas meninas e adolescentes precisam abandonar a escola devido à gravidez, o que tem um impacto de longo prazo nas oportunidades de completar sua educação e se incorporar ao mundo do trabalho. De acordo com o Guia Prático de Atualização para a Prevenção da Gravidez na Adolescência da Sociedade Brasileira de Pediatria $^{2}$, as mães adolescentes estão expostas a situações de maior vulnerabilidade e a reproduzir padrões de pobreza e exclusão social.

Diante disso, este estudo possuiu como objetivo geral, identificar os conflitos percebidos e vivenciados por adolescentes grávidas. Como objetivos específicos, caracterizar o perfil sociodemográfico das participantes; relacionar os sentimentos experimentados e as necessidades sentidas pelas adolescentes gestantes; e compreender as principais dificuldades físicas, emocionais e sociais decorrentes de uma gravidez precoce.

\section{METODOLOGIA}

Trata-se de uma pesquisa de campo, do tipo descritiva e de natureza qualitativa. A pesquisa qualitativa possibilita um aprofundamento de situações e fenômenos parecidos, 
contribuindo para a construção de novos modelos e procedimentos. Optamos pela pesquisa qualitativa por entender que essa metodologia é a mais apropriada aos objetivos do presente estudo.

O investigador clínico-qualitativista não possuiu como objetivo demonstrar como um fenômeno se comporta numericamente, mas seu alvo de interesse são as significações/significados que um indivíduo ou grupo atribuem aos fenômenos da natureza que lhes dizem respeito. Sendo assim, foi contemplado o estudo da subjetividade ocupando-se com a elucidação e o conhecimento dos processos de significação que a constituem. "As significações são obtidas através da fala e do comportamento das pessoas ou da comunidade em estudo" ${ }^{3}$

O estudo foi realizado na cidade de João Pessoa - PB e contou com a participação de três adolescentes com idade entre 14 a 17 anos, que estavam grávidas, a partir do 3 mês de gestação. Em relação ao critério de escolha das participantes, utilizou-se o critério de inclusão proposital, também denominada intencional ou deliberada. Por esse critério, o pesquisador escolheu deliberadamente as participantes que compuseram o estudo de acordo com os objetivos do trabalho, desde que pudessem fornecer as informações pertinentes ao mesmo.

Com a obtenção da aprovação do Comitê de Ética em Pesquisa ( Número do Registro CAAE: 99494718.3.00oo.5179) iniciou-se a coleta de dados, em foram utilizados os seguintes instrumentos: Questionário sociodemográficos e Entrevista semiestruturada, composta de questões que atendem aos objetivos propostos. A entrevista orienta "uma conversa com finalidade, servindo como facilitadora de abertura, ampliação e aprofundamento da comunicação" ${ }^{4}$. Obtendo-se assim informações e opiniões pertinentes ao estudo.

Obedecendo a Resolução 466/12, do Conselho Nacional de Saúde, o qual garante sigilo, anonimato e consentimento informado ao participante e a autorização dos responsáveis pelas adolescentes, elas foram procuradas numa policlínica de saúde e foram convidadas a participar sendo informadas elas e seus responsáveis sobre as informações pertinentes ao estudo. As interessadas, com disponibilidade de participação e que 
contemplavam os critérios de inclusão da pesquisa foram informadas dos objetivos da pesquisa, sendo também garantido o sigilo acerca das informações. Cumprindo com as orientações éticas, foi esclarecido e solicitado ao responsável, a assinatura do Termo de Consentimento Livre e Esclarecido autorizando a participação das adolescentes na pesquisa. Esclarecemos ainda que tanto sua autorização, como a participação da adolescente no estudo foi voluntária e, portanto, não foram obrigados a fornecer as informações e/ou colaborar com as atividades solicitadas pelo Pesquisador (a). Caso decidissem não participar do estudo, ou resolvessem a qualquer momento desistir do mesmo, não sofreriam nenhum dano ou prejuízo. Assim, a entrevista foi agendada numa sala da policlínica, realizada individualmente, novamente explicou-se como ocorreria a participação delas nesse estudo proposto e assinaram o "Termo de Consentimento Livre e Esclarecido".

A análise dos instrumentos utilizados realizou-se de forma qualitativa, com o conteúdo mobilizado na entrevista semiestruturada de acordo com a Análise de Conteúdo, especificamente a Análise Temática. Segundo Minayo", ela consiste "em descobrir os núcleos de sentido que compõem uma comunicação cuja presença ou frequência signifiquem alguma coisa para o objetivo analítico visado". Dessa forma, foram abordados os temas predominantes nas falas dos participantes e analisados com base no referencial teórico elaborado.

Para a realização desta pesquisa, foram levados em consideração os pressupostos da Resolução 466/2012 do Conselho Nacional de Saúde/Ministério da Saúde que trata de pesquisas e testes em seres humanos ${ }^{5}$ e em conformidade ao Estatuto da Criança e do Adolescente (ECA) - Lei Federal no $8.069 / 1990^{6}$.

\section{RESULTADOS E DISCUSSÃO}

A Tabela I apresenta os dados sociodemográficos das entrevistadas, ressaltando-se que o nome das adolescentes não será exposto, para preservar a identidade delas. 
Tabela r: Apresentação dos dados sociodemográficos das participantes. João Pessoa-PB, 2019 .

\begin{tabular}{|c|c|c|c|}
\hline DADOS & ENTREVISTADA A & ENTREVISTAD B & ENTREVISTADA C \\
\hline $\begin{array}{l}\text { Idade } \\
\text { Estado civil } \\
\text { Escolaridade }\end{array}$ & $\begin{array}{c}\text { I7anos } \\
\text { solteira }\end{array}$ & $\begin{array}{c}\text { I7anos } \\
\text { casada } \\
\text { ensino médio } \\
\text { incompleto }\end{array}$ & $\begin{array}{c}\text { I7anos } \\
\text { solteira } \\
\text { ensino médio } \\
\text { incompleto }\end{array}$ \\
\hline Classe social & classe média & classe baixa & classe baixa \\
\hline $\begin{array}{l}\text { Primípara } \\
\text { Tempo de } \\
\text { gestação }\end{array}$ & 24 semanas & 24 semanas & 27 semanas \\
\hline $\begin{array}{l}\text { Com quem } \\
\text { reside }\end{array}$ & pais e irmão & pais, irmãos e cônjuge & mãe \\
\hline
\end{tabular}

Fonte: Elaboração Própria

De acordo com os dados apresentados ( Tabela I ), se verifica que a amostra foi composta por três adolescentes com 17 anos de idade, sendo todas residentes de cidades interioranas do estado da Pará́ba. A maioria não completou o ensino médio pois, pela vivência de uma gestação precoce, tiveram que se ausentar da vida acadêmica. As jovens estão grávidas pela primeira vez, sendo apenas uma delas casada. A maioria é de classe baixa e dependente dos pais para a subsistência.

De acordo com a OPAS ${ }^{\mathrm{I}}$, a taxa mundial de gravidez adolescente é estimada em 46 nascimentos para cada i mil meninas de is a 19 anos, enquanto a taxa na América Latina e no Caribe é estimada em 65,5 nascimentos, superada apenas pela África Subsaariana, segundo relatório "Aceleração do progresso para a redução da gravidez na adolescência na América Latina e no Caribe“, no Brasil, a taxa é de 68,4.

É necessária uma reflexão para se entender os motivos que levam essas meninas a engravidar, considerando esse acontecimento como multicausal. Alguns fatores contribuem para a gravidez precoce, dentre eles a ingenuidade, a submissão, a violência, as 
dificuldades de obter algum método contraceptivo, as expectativas de mudança de status social ou outros fatores ligados à subjetividade da adolescente ${ }^{7}$.

Sendo assim, a partir das entrevistas realizadas foi estabelecido um roteiro orientador que contemplasse as experiências vivenciadas pelas participantes sobre a gravidez na adolescência. Dessa forma, emergiram três categorias de análise:

I) Importância da Família

2) Dilemas da Gestação Precoce

3) Expectativas das jovens mães

Essas categorias são apresentadas e discutidas a seguir.

\section{IMPORTÂNCIA DA FAMÍLIA}

Apesar de ser notadamente perceptível o receio das adolescentes em se pronunciarem sobre sua gestação em seus respectivos âmbitos familiares, tentamos obter o máximo de sentimentos de cada uma, tornando-se explícito que existe um certo grau de arrependimento diante da situação.

Identificou-se no depoimento da Entrevistada C, participante dessa pesquisa, seu desapontamento em manter uma relação bastante distante com seu pai:

Meu pai não me criou, sempre foi só minha mãe e eu. Ela tá mais animada que eu com a descoberta da minha gravidez, se ele tivesse aqui com a gente eu não sei como seria a reação dele, ou como teria sido nossa vida" (ENTREVISTADA C,I7 ANOS, 27 SEMANAS).

A escolha de amigos e de namorados que os pais desaprovam contribuem para o agravamento das dificuldades relacionais presentes na adolescência.

A Entrevistada B relatou a sensação de medo perante seu pai e o apoio encontrado na sua mãe:

Eu me dou mais com minha mãe, no começo foi difícil pra contar pro meu pai sobre minha gravidez porque ele odeia meu namorado e se não fosse ela pra me defender, ele nem sei o que ele teria feito comigo e com meu namorado" (ENTREVISTADA B, i7 ANOS, 24 SEMANAS).

O relacionamento com os pais, frente à gestação, fica de certa forma abalada. Eles se posicionaram como "obrigados" a aceitar a gestação, resultando num comportamento distante e em alguns casos frio em relação à adolescente e ao bebê. A fala de uma das participantes indica esse comportamento: 
Meu pai tem me desprezado desde que soube da minha gravidez e minha mãe evita falar do assunto com nossos parentes, até porque meu namorado não trabalha, sinto que ela tem desgosto de mim e que sou uma decepção em minha casa" (ENTREVISTADA A, i7 ANOS, 24 SEMANAS).

Apesar desse choque inicial vivido pelos familiares, fica claro na fala das entrevistadas a importância do apoio familiar para que as adolescentes consigam lidar com a gestação numa fase precoce da vida. Etapa essa em que muitos sonhos são deixados de lado para darem prosseguimento aos cuidados com o bebê que está sendo gerado e com as mudanças corporais, psíquicas e emocionais experenciadas.

Diante das informações citadas pelas adolescentes entrevistadas, percebeu-se que, de fato, no início a gestação foi encarada como um problema, mas com o passar do tempo, a nova realidade foi aceita como componente que também faria parte do sistema familiar a partir de então. Além disso, as famílias das jovens enfrentaram mudanças no sentido de perceber a filha como mãe, o que culmina na passagem de "menina para mulher". Em resumo, a família representa um núcleo importante de compreensão que irá contribuir para as perspectivas das adolescentes no presente e, principalmente, no futuro.

\section{DILEMAS DA GESTAÇÃO PRECOCE}

Dentre as dificuldades relatadas que envolvem as famílias das jovens, a falta de independência e de autonomia foram bem elucidadas. A Entrevistada A declarou de modo claro sobre tal dilema:

\footnotetext{
Agora que já tô grávida não adianta mais nada, mas no começo fiquei mal que só porque pra tudo eu dependo dos meus pais, principalmente da minha mãe...e para ser sincera têm certas situações que eu não vou saber decidir sozinha, eu preciso deles comigo" (ENTREVISTADA A, i7 ANOS, 24 SEMANAS).
}

A adolescente grávida vive um tempo de medos e anseios, adicionado à obtenção de uma nova identidade que ainda não está amadurecida suficientemente para receber e, principalmente para a exigência que a sociedade ocasionará a este novo papel. Entre as várias implicações psicossociais podemos citar como mais preocupante a suspensão da frequência na escola e do prejuízo na formação profissional ${ }^{8}$. A Entrevistada $C$ revelou sua frustação em se deparar com o julgamento da sociedade e se mostrou pressionada com a repercussão da sua gestação:

Foi tão constrangedor ver o pessoal da rua fofocando sobre mim, porque eu engravidei e parei logo a escola, naquele momento eu percebi que tinha que ser 
forte de todo jeito mesmo sabendo que essa maturidade não vem da noite pro dia" (ENTREVISTADA C, 17 ANOS, 27 SEMANAS)

Diante disso, foi possível verificar em nosso estudo que as jovens possuem a consciência de que, a partir do momento que seus filhos nascerem, a rotina mudará por completo, incluindo o afastamento das amigas, o que de certa forma irá privar a jovem mãe do convívio social. A mudança na rotina e na perspectiva das jovens participantes indica o quanto é desafiadora a missão de conciliar a vida de adolescente com a maternidade, visto que, é na adolescência que ocorre uma profunda desestruturação da personalidade e transição para a vida adulta.

Maia, Verdi e Graziano ${ }^{9}$ afirmam que, em muitos casos, a gestação na adolescência é vivenciada com dificuldade, uma vez que a adolescente vive uma situação conflituosa durante a transição do seu papel de mulher em formação para o de mulher-mãe. Esse conflito pode ser consequência do despreparo físico, psicológico, social e econômico para o exercício do papel materno.

No caso da Entrevistada A, a situação foi ainda mais agravante pois a jovem estava cursando uma graduação em Enfermagem quando engravidou, devido a isso, seu sentimento de reflexão foi mais profundo:

\section{Eu tava na faculdade, fazendo o curso do meu sonho, tinha bolsa e tudo, mas tive que trancar para poder ter meu filho. Eu não tenho com quem deixar meu filho porque minha mãe trabalha, mas tenho fé que Deus vai me ajudar" (ENTREVISTADA A, 17 ANOS, 24 SEMANAS).}

No Tratado de Pediatria da Sociedade Brasileira de Pediatria, Campos Júnior ${ }^{\text {Io }}$ refere outras situações de risco para o filho de mãe adolescente, são elas: abandono, maior número de reinternações e violência por falta de paciência e autocontrole com a nova responsabilidade. Tais situações de risco acarretam em danos psicossociais como tensão emocional com maior probabilidade de desenvolver problemas físicos e mentais, rejeição familiar, vergonha, depressão que pode levar ao suicídio, perda do companheiro.

Em consonância aos danos psicossociais estão os agravos físicos, os quais refletem significantemente na saúde das jovens mães, por exemplo hipertensão (as situações de préeclâmpsia e eclâmpsia são resultados de controle pré-natal insuficiente ou ausente ou de outros fatores intervenientes e agravantes); anemias (encontradas em situações de pobreza, subnutrição e desnutrição crônica); maior índice de cesárea; laceração perineais 
envolvendo vagina e perineais; infecções urinárias e genitais; mortalidade materna (o risco quanto menor for a idade cronológica e com gestações sucessivas e em intervalos curtos; abortos clandestinos levando a complicações e mortes ${ }^{\mathrm{IO}}$.

\section{EXPECTATIVAS DAS JOVENS MÃES}

Nosso estudo revelou que as adolescentes grávidas possuem diversas expectativas em relação ao futuro, ao filho e à maternidade e que, apesar de estarem vivenciando uma experiência que contribui para um novo caminho cheio de transformações, continuam almejando sonhos e desejos de meninas. Contudo, foi notório que a partir de então, o bebê se encontra no centro de todas as idealizações para o futuro das jovens mães.

Uma das expectativas mais frequentes em nossa entrevista foi em relação à vontade das jovens entrevistas de terminar os estudos para poder proporcionar uma vida confortável para seu filho. Daí, consegue-se perceber que as adolescentes possuem a consciência de que uma formação acadêmica viabiliza oportunidades para que nada falte para ela e para o filho. A Entrevistada A destacou a sua expectativa no tocante aos seus estudos:

Pretendo terminar meus estudos para propiciar uma boa qualidade de vida ao meu filho, trabalhar e assim, conquistar a independência, o que mais quero é que ele não passe necessidade como eu já passei” (ENTREVISTADA A, i7 ANOS, 27 SEMANAS).

Nessa pesquisa foi possível identificar o vínculo afetivo já sendo construído entre a mãe e o bebê. Quando questionadas sobre suas expectativas para com seus filhos foram seguras ao expressar que fariam tudo por eles e que estariam dispostas a enfrentar todas as possíveis dificuldades. Apesar disso, demonstraram uma consciência de que a maternidade precoce exigiria muita dedicação quanto aos cuidados com o bebê. A Entrevistada B nos chamou atenção pela sua simplicidade ao assumir a mistura de sentimentos em relação ao filho:

Ele ainda tá aqui na minha barriga mas já amo tanto...nem sei explicar uma amor tão grande. Mas também eu fico com aquele medo de não conseguir dar conta porque tem que cuidar, segurar, dar banho. Tenho medo de não ser uma boa mãe" (ENTREVISTADA B, i7 ANOS, 24 SEMANAS).

A literatura apresenta que o receio na capacidade de cuidar do bebê é um sentimento mais associado ao fato de ser primípara, posto que, as mudanças são mais 
importantes na primeira gestação. A incerteza das gestantes quanto ao seu futuro e desempenho como mãe é reflexo da deficiência de informações, que para elas é um fator limitante no exercício do papel

materno, provocando medo de assumir os cuidados com o bebê, além de surgirem várias dúvidas e dificuldades ${ }^{7}$.

A Entrevistada A mostrou um certo grau de desespero em relação ao que espera do seu futuro a partir do nascimento do seu filho:

Eu fico preocupada porque como vai ser, né? Meu namorado tá nem aí. Meus pais trabalham pra sustentar a casa mas eu queria terminar a faculdade. Não vai ter quem fique com meu filho pra eu poder ir estudar. Ele nem nasceu e eu já tô me estressando tanto" (ENTREVISTADA A, 17 ANOS, 24 SEMANAS).

É, portanto, de modo gradual que a adolescente constrói sua concepção de mãe, vivendo à sua maneira e com ritmo próprio esse reconhecimento do filho, assumindo suas responsabilidades e passando a se sentir mais segura e confiante quanto à capacidade de ser mãe.

Nesse viés, a partir dessa análise surge a necessidade de executar estratégias educativas integrando setores como a saúde e a educação, efetivando as diretrizes políticas existentes, possibilitando às jovens mães escolhas que favoreçam o desenvolvimento pessoal, social e com foco na promoção da saúde sexual e reprodutiva.

A partir dos resultados obtidos foi possível compreender que agravidez na adolescência éumfenômeno heterogêneo, que sofre elevada influência do contexto socialemque adolescente está inserida. Identifica-se claramente que a gestação na adolescência tem grandes impactos, como por exemplo, o abandono das atividades escolares, visto que a maioria dessas adolescentes não chegam a concluir o ensino médio.

Há ainda a abdicação do lazer com alteração na rotina e no estilo de vida por causa da gestação, além dos desafios familiares experimentados pelas jovens, que foram evidenciados nesse estudo, entre eles se destaca a relação intrínseca entre a gravidez na adolescência e a privação da figura paterna vivida pelas jovens e que tal fato possivelmente repercutiu na busca por um companheiro por essas adolescentes para o suprimento dessa carência. 

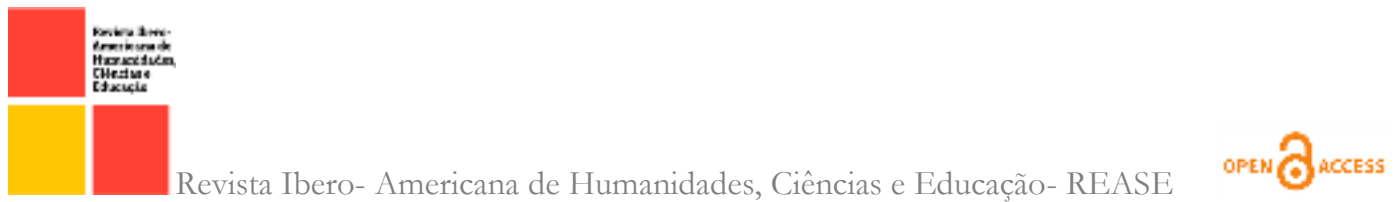

Observa-se que as jovens mães já possuem certo grau de afetividade por seu bebê acompanhado de amplo espectro de sentimentos, os quais foram citados como: medo de não saber como proceder em certas situações com o filho, desapontamento pela não aprovação de algum membro da família, assim como adicionar o filho em seus planos e apresentarem a expectativa de educá-los da melhor forma possível.

Foi notável ainda que, apesar das dificuldades e desafios enfrentados pelas adolescentes entrevistadas, muitas guardam seus sonhos de concretizarem o término dos estudos, a fim de proporcionar uma melhor qualidade de vida para os seus filhos. Isso deixa claro que elas são providas de uma consciência sobre a importância da educação na economia familiar e o amor por seu bebê. Além disso, se verificou que o apoio familiar e do cônjuge nessa nova fase é imprescindível para que a adolescente se sinta segura e possa enfrentar de uma maneira mais adequada às mudanças geradas em sua vida devido a gestação.

Em relação às limitações desse estudo, se pode indicar o número reduzido de adolescentes grávidas. Como possibilidades para outras pesquisas sugerem-se estudos comparativos de adolescentes grávidas de classes baixa em relação à classe alta e como essa vivência repercute em seus contextos sociais, já que a condição financeira, o aporte educacional e a base familiar podem interferir de maneira significativa no modo de pensar e agir da adolescente.

\section{REFERÊNCIAS}

I. OPS (Organización Panamericana de la Salud). Acelerar el progreso hacia la reducción del embarazo en la adolescencia en América Latina y el Caribe. Organización Panamericana de la Salud, Fondo de Población de las Naciones Unidas y Fondo de las Naciones Unidas para la Infancia. Washington, D.C., Estados Unidos de América; 2018.

2. Sociedade Brasileira de Pediatria. Prevenção da Gravidez na Adolescência: Guia Prático de Atualização. Departamento Científico de Adolescência, nํㅡㅁ, Janeiro de 2019.

3. Turato ER. Tratado da metodologia da pesquisa clínico-qualitativa: construção teóricoepistemológica, discussão comparada e aplicação nas áreas da saúde e humanas. Petrópolis. 2003.

4. Minayo MC. O desafio do conhecimento: pesquisa qualitativa em saúde. São Paulo: Hucitec na análise dos dados temática, 2014. 
5. BRASIL. Ministério da Saúde. Conselho Nacional de Saúde. Resolução 466/2012. Brasília, DF: Ministério da Saúde, 12 de dez. De 2012. [acesso em: 23 nov. de 2018]. Disponível em:https://bvsms.saude.gov.br/bvs/saudelegis/cns/2013/reso466_I2_12_2012.html

6. BRASIL. Lei no 8.069, de 13 de julho de 1990. Dispõe sobre o Estatuto da Criança e do Adolescente e dá outras providências. Diário Oficial [da] República Federativa do Brasil, Brasília, DF, i6 jul. 1990. [Acesso em: 20 dez. 2018]. Disponível em:http://www.planalto.gov.br/ccivil_03/leis/18069.htm.

7. Martins LWF, Frizzo GB, Diehl AMP. A constelação da maternidade na gestação adolescente: um estudo de casos. Psicologia USP, vol.25, n.3, 2014, p.294-306.

8. Barboza MF. Dilemas e desafios gravidez na adolescência. Universidade José Do Rosário Vellano. Webartigos, 24 de mai. de 2017.

9. Maia JS, Verdi RA, Graziano V.A gravidez precoce e seus desdobramentos. Revista Científica Multidisciplinar Núcleo do Conhecimento, o4(4), Ed. 02, 2019, p. 82-97.

ıo. Campos Júnior D, Burns DAR. Tratado de Pediatria da Sociedade Brasileira de Pediatria. 3 edição, Barueri, SP: Manole, 2014. 